Egypt. Acad. J. Biolog. Sci., 12(2):57-69 (2020)

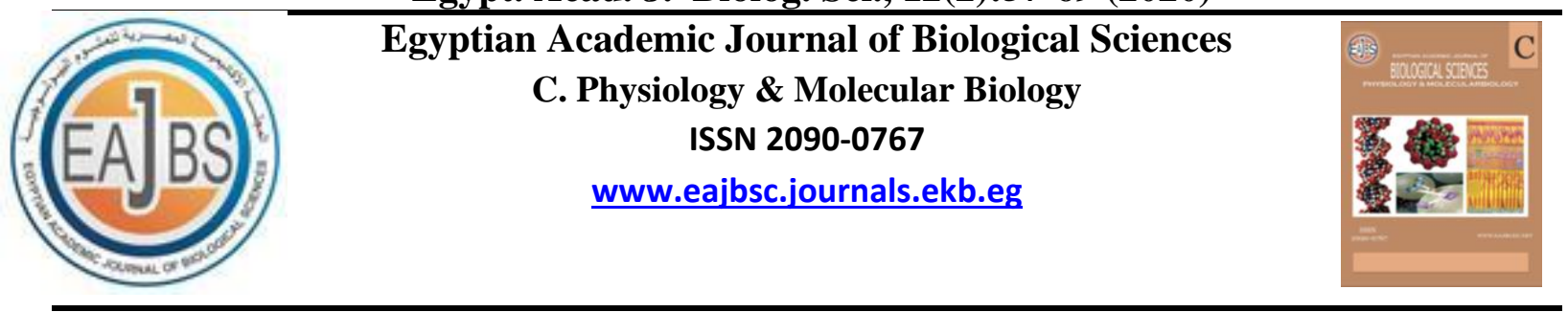

\title{
Molecular Analysis For Salt Tolerance QTLs Emphasizing Saltol QTL in Some Egyptian and International Rice Genotypes (Oryza sativa L.)
}

\author{
Ebrahim A. Ramadan*, Mahrous Negm, and Mohamed A. Abdelrahman* \\ Rice Research and Training Center, Field Crops Research Institute, Agricultural Research \\ Center, Sakha 33717, Kafrelsheikh, Egypt. \\ E.Mail: ibrahim_rrtc@yahoo.com; abdelrahman.rrtc@gmail.com
}

\section{ARTICLE INFO}

Article History

Received: $19 / 6 / 2020$

Accepted: 21/ 8/2020

Keywords:

Saltol, QTL,

Salinity, rice,

Egyptian rice

cultivars.

\section{ABSTRACT}

Rice (Oryza sativa, L.) is one of the strategic crops in Egypt, and the improvement of its productivity is an essential requirement to ensure food security. Salinity is one of the major environmental stresses that limit the productivity of rice crop. 14 SSR markers linked to salinity were used to study the genetic diversity within salinity tolerance QTLs in 18 rice genotypes. All the utilized primers were polymorphic, the number of alleles ranged from 2 to 6 with an average of 3.42 per locus. The major frequency alleles ranged from 0.33 to 0.78 for RM562 and RM412, respectively. The PIC values varied from 0.79 to 0.37 with an average of 0.50. Seven SSR markers i.e. RM562, RM493, RM1287, RM223, RM242, RM10720, and RM5 were informative markers with PIC values more than 50\%. Jaccard's similarity coefficients ranged from 0.07 to 0.93 with an average of 0.45 . The studied genotypes were grouped into two major clusters at 0.18 similarity. The PCA analysis had the ability to classify the studied genotypes into clearly four separate clusters based on the origin and salinity tolerance. 13 haplotypes other than the reference haplotype were identified. The number of genotypes per haplotype ranged from one to five. The current investigation highlighted the high amount of genetic diversity among the studied genotypes. Egyptian Yasmine, the fragrant genotype, was the most promising genotype where it has 50\% of Pokkali alleles at Saltol QTL region and this makes it suitable to be used as salt tolerance donor for MAS in salinity tolerance molecular breeding program.

\section{INTRODUCTION}

Rice is the most important crop being the dominant food in most of the countries around the world. In Egypt, rice is considered among the most adapted summer crops to the salt-affected coastal areas. Rice can withstand water-logging and standing water helps in diluting and leaching salts from surface soil (Ismail et al., 2008). According to the final report of the geological society of America, sea level is rising annually $3 \mathrm{~mm}$ on average and the current saline intrusion reaches the central delta sectors (Stanley and Clemente, 2017). Moreover, Egypt's freshwater is decreasing at alarming rates which will cause the problem to be worse in the upcoming years. Accordingly, salinity considered one of the major abiotic stresses affecting rice sustainability and yield. Rice scientists in Egypt at Rice Research and Training Center (RRTC) have long worked on developing new cultivars and promising lines to overcome adverse environments for rice cultivation, among these cultivars Sakha104, Giza178 and Giza179 (Zayed et al., 2017). 
Molecular markers are tools that play an important role in identifying genotypes that are promising under salinity affected soils. These tools have been long used for identifying QTL regions closely linked to several biotic and abiotic stresses related traits. Furthermore, they were used for assisting breeders to identify breeding lines carrying specific genomic regions acting for tolerance to unfavorable environments through marker-assisted selection. They also can be applied at different growth stages and with different methodologies and types.

Among molecular markers, microsatellites markers or simple sequence repeats which are commonly known as SSR markers have advantages over other markers. These markers are short repeated motifs that are abundant in the genomes and vary in the number of repeats at a given locus ( $\mathrm{Wu}$ and Tanksley, 1993; Akagi et al., 1996; McCouch et al., 1997). The SSR markers revealed a high ability in estimating genetic diversity and genetic relationships among plant species, populations, or individuals (Ganie and Mondal 2015), and markerassisted selection (MAS) breeding (Rani and Adilakshmi 2011). The ease of conducting and their distribution across the genome make them the markers of choice in many studies. SSR markers have been used in genetic diversity studies, parentage selection, and mapping genomic regions.

Saltol QTL is a major salt tolerance QTL located on chromosome 1. It was identified by Gregorio (1997) in a recombinant inbred line population derived from the cross Pokkali/IR29. Saltol QTL governed the $\mathrm{Na}^{+} / \mathrm{K}^{+}$uptake ratio and accounted for 64.3 to $80.2 \%$ of the phenotypic variation of salt tolerance at the seedling stage (Bonilla et al., 2002). This segment of chromosome 1 was further fine mapped by using SSR markers (Niones, 2004). Progressing research identified some salt tolerance genes in this region as like Shoot $K^{+}$content 1 (SKCl) gene, the Pokkali derived locus which encodes a $\mathrm{Na}^{+}$selective ion transporter (Ren at al., 2005). Several studies reported that Saltol QTL was detected in some other rice varieties (Takehisa et al., 2004 and Ren et al., 2005).

The aim of the current study is to investigate the existed diversity among some salt-tolerant international donors as well as Egyptian rice cultivars and some promising lines using SSR markers with more emphasis on the Saltol genomic region. The best to our knowledge the current research is the first report to emphasize the genetic diversity among the Egyptian cultivars in the Saltol locus.

\section{MATERAILS AND METHODS}

\section{Plant Material:}

Eighteen rice genotypes, Table 1, collected from Rice Research and Training Center (RRTC), Kafr El-Sheikh, Egypt, during the growing season 2019/2020, with different responses to salinity stress were used for assessment of genetic diversity in salt tolerance QTLs.

\section{Genomic DNA Isolation:}

Leaves of fourteen days seedlings were harvested from each genotype. Genomic DNA was isolated from 3-4 g of bulked leaf samples following Cetyl Trimethyl Ammonium Bromide (CTAB) method (Murray and Thompson, 1980). The DNA quantity and quality were estimated with $0.8 \%$ agarose gel electrophoresis using a known concentration of Lambda DNA as a size standard. The DNA samples were diluted in $\mathrm{T}_{10} \mathrm{E}_{1}(10 \mathrm{mM}$ Tris- $\mathrm{HCl}, 1 \mathrm{mM}$ EDTA, pH 8.0) buffer to get a final concentration of $15 \mathrm{ng} / \mathrm{ul}$ which is suitable for PCR amplification. 
Table 1. List of the studied rice genotypes, their salinity response, subtype and origin.

\begin{tabular}{|c|l|c|c|c|}
\hline No. & \multicolumn{1}{|c|}{ Genotypes } & Description & Origin & $\begin{array}{c}\text { Salt tolerance } \\
\text { reaction }\end{array}$ \\
\hline 1 & Agami M1 & Japonica & Egypt & $\mathrm{T}$ \\
\hline 2 & Nona bokra & Indica & India & $\mathrm{T}$ \\
\hline 3 & Pokkali & Indica & India & $\mathrm{T}$ \\
\hline 4 & IR72 & Indica & Philippine & MT \\
\hline 5 & IR29 & Indica & Philippine & $\mathrm{S}$ \\
\hline 6 & Giza178 & Indica/Japonica & Egypt & $\mathrm{T}$ \\
\hline 7 & Giza179 & Indica/Japonica & Egypt & $\mathrm{T}$ \\
\hline 8 & GZ1368-S-5 & Indica & Egypt & $\mathrm{T}$ \\
\hline 9 & GZ9399-4-1-1-3-2-2 & Indica/Japonica & Egypt & $\mathrm{T}$ \\
\hline 10 & Sakha104 & Japonica & Egypt & $\mathrm{MT}$ \\
\hline 11 & Giza177 & Japonica & Egypt & $\mathrm{S}$ \\
\hline 12 & Sakha101 & Japonica & Egypt & $\mathrm{S}$ \\
\hline 13 & Sakha102 & Japonica & Egypt & $\mathrm{S}$ \\
\hline 14 & Sakha103 & Japonica & Egypt & $\mathrm{S}$ \\
\hline 15 & Sakha105 & Japonica & Egypt & $\mathrm{S}$ \\
\hline 16 & Sakha106 & Japonica & Egypt & $\mathrm{S}$ \\
\hline 17 & Sakha107 & Japonica & Egypt & MT \\
\hline 18 & Egyptian Yasmine & Indica & Egypt & MT \\
\hline
\end{tabular}

Where, T is tolerant, MT is moderately tolerant and S is susceptible

PCR Amplification And Gel Electrophoresis:

A set of 14 SSR markers were used in the current study (Table 2), out of them 12 markers are covering the saltol genomic region. The original source, repeat motifs, primer sequences, annealing temperature, and chromosomal location are found in the Gramene website (https://archive.gramene.org/). The PCR amplification reactions were carried out in $15 \mu \mathrm{l}$ reaction mixtures, containing $1.5 \mu \mathrm{l}$ of template DNA, $1 \mu \mathrm{l}$ of each forward and reverse SSR primers, $7.5 \mu \mathrm{l}$ of PCR master mix (ROVALAB 2x Red PCR Master Mix, kantstr, Germany) and $4.5 \mu \mathrm{l} \mathrm{dd}_{2} \mathrm{O}$. All amplifications were performed in a thermal cycler (PerkinElmer, geneamp PCR system 2400) using the following parameters: initial denaturation at $94^{\circ} \mathrm{C}$ for $5 \mathrm{~min}$.; followed by 35 cycles of denaturation at $94^{\circ} \mathrm{C}$ for $1 \mathrm{~min}$., annealing at $55^{\circ} \mathrm{C}$ for $30 \mathrm{sec}$., and extension at $72^{\circ} \mathrm{C}$ for 1 minute; and a final extension at $72^{\circ} \mathrm{C}$ for $7 \mathrm{~min}$. The amplified products were separated electrophoretically on 3\% Agarose gels using 0.5X TAE buffer and stained with ethidium bromide $(0.5 \mu \mathrm{g} / \mathrm{ml})$. The gels were visualized and photographed using a gel documentation system (Biometra, Biodoc analyze) to detect the amplified DNA fragments. Sizes of the amplified DNA bands were determined based on the migration of the amplified band relative to the standard molecular size DNA marker (50 bp DNA ladder, MBI Fermentas). 
Table 2: Chromosome number, Marker Loci, repeat motif, and forward and reverse primers sequences of the 14 used SSR markers

\begin{tabular}{|c|c|c|c|c|c|c|}
\hline No. & $\begin{array}{c}\text { Marker } \\
\text { Accession }\end{array}$ & $\begin{array}{c}\text { Chr. } \\
\text { no }\end{array}$ & Position (bp)* & Repeat Motif & Forward & Reverse \\
\hline 1 & RM1287 & 1 & $10,838,376-10,838,538$ & $(\mathrm{AG}) 17$ & GTGAAGAAAGCATGGTAAATG & CTCAGCTTGCTTGTGGTTAG \\
\hline 2 & RM10711 & 1 & $11,161,114-11,161,286$ & \begin{tabular}{|l}
$(\mathrm{GAG}) 9$ \\
\end{tabular} & GCTTCGATCGATGAGAAAGTAGAGG & GAATCTCCCATCCTTCCCTTCC \\
\hline 3 & RM10720 & 1 & $11,394,704-11,394,908$ & $(\mathrm{TA}) 34$ & GCAAACGTCTACGTGAGAAACAAGC & GCATGTGGTGCCTTAACATTTGG \\
\hline 4 & RM10772 & 1 & $12,160,175-12,160,570$ & (CTT)16 & GCACACCATGCAAATCAATGC & CAGAAACCTCATCTCCACCTTCC \\
\hline 5 & RM493 & 1 & $12,280,117-12,280,294$ & (CTT) 9 & TAGCTCCAACAGGATCGACC & GTACGTAAACGCGGAAGGTG \\
\hline 6 & RM140 & 1 & $12,300,716-12,301,015$ & (CT) 12 & TGCCTCTTCCCTGGCTCCCCTG & GGCATGCCGAATGAAATGCATG \\
\hline 7 & RM10825 & 1 & $13,322,227-13,322,324$ & (AAG)10 & GGACACAAGTCCATGATCCTATCC & GTTTCCTTTCCATCCTTGTTGC \\
\hline 8 & RM562 & 1 & $14,626,324-14,626,568$ & (AAG)13 & CACAACCCACAAACAGCAAG & CTTCCCCAAAGTTTTAGCC \\
\hline 9 & RM9 & 1 & $23,325,018-23,325,199$ & (GA)15GT(GA)2 & GGTGCCATTGTCGTCCTC & ACGGCCCTCATCACCTTC \\
\hline 10 & RM5 & 1 & $23,971,321-23,971,514$ & $(\mathrm{GA}) 14$ & TGCAACTTCTAGCTGCTCGA & GCATCCGATCTTGATGGG \\
\hline 11 & RM212 & 1 & $33,053,493-33,053,654$ & (CT) 24 & CCACTTTCAGCTACTACCAG & CACCCATTTGTCTCTCATTATG \\
\hline 12 & RM315 & 1 & $36,734,135-36,734,272$ & (AT)4(GT) 10 & GAGGTACTTCCTCCGTTTCAC & AGTCAGCTCACTGTGCAGTG \\
\hline 13 & RM223 & 8 & $20,650,060-20,650,244$ & (CT) 25 & GAGTGAGCTTGGGCTGAAAC & GAAGGCAAGTCTTGGCACTG \\
\hline 14 & RM242 & 9 & $18,810,067-18,810,331$ & (CT) 26 & GGCCAACGTGTGTATGTCTC & TATATGCCAAGACGGATGGG \\
\hline
\end{tabular}

*Positions according to Gramene annotated nipponbare sequence 2019

\section{Data Analysis:}

The amplified DNA bands (alleles) were scored for each genotype and primer combination. Data were entered into a binary matrix and subsequently analyzed using the computer software package, PowerMarker (Version 3.25) (Liu and Muse, 2005). The total number of alleles per locus, Major allele frequency, and total allele frequency were calculated. The effective number of alleles per locus $\left(A_{e p}\right)$ were estimated according to Weir (1989) $\left(A_{e p}=\frac{1}{1-H_{e}}\right)$, where $H_{e}$ is the genetic diversity per locus. Polymorphism information content (PIC) was calculated to assess allele diversity of a marker locus according to Anderson et al. (1993) using the following formula: $P I C_{i}=1-\sum_{j=1}^{n} P_{i j}^{2}$, where $P_{i j}$ is the frequency of $i^{\text {th }}$ allele for the $j^{\text {th }}$ locus and the summation extend over $n$ alleles. Darwin 6.0.0.21 was used for genetic similarity coefficients estimation and constructing the dendrogram using the unweighted pair group method using arithmetic averages (UPGMA). Principal component analysis (PCA) also was carried out. Similarity index (SI) among all pairs of the 18 rice genotypes were estimated according to the equation: $S I=2 N_{i j} /\left(N_{i}+N_{j}\right)$, where, $N_{i j}$ is the number of bands common to genotypes $i$ and $j$ and $\left(N_{i}+N_{j}\right)$ is the total number of fragments in both genotypes (Nei and $\mathrm{Li}$, 1979).

\section{RESULTS AND DISCUSSION}

Molecular analysis and genetic diversity for salinity tolerance were studied in different rice genotypes using different types of markers (Reddy et al., 2017). Microsatellites or SSR markers are the most appropriate markers for study the genetic diversity compared with other DNA markers due to their multi-allelic nature, co-dominant inheritance, abundance, and extensive genome coverage (Orjuela et al., 2010). In the current study, genetic diversity for salt tolerance QTLs was studied among 18 different Egyptian and international rice genotypes. 14 SSR markers related to salt tolerance QTLs were used to evaluate allelic diversity, gene diversity, polymorphism information content (PIC), and genetic relationships among the studied genotypes.

The results of the molecular analysis are found in Table 3. All the utilized primers were polymorphic with a total of 48 reproducible DNA bands/alleles. The number of alleles per locus ranged from 2 for RM9 and RM10825 to 6 for RM562 (Fig. 1) with an average of 3.42. The effective number of alleles ranged from 1.61 and 5.26 with an average of 2.45 allele per locus. These results indicated the existence of high allelic diversity in salt tolerance QTLs among the tested genotypes. Furthermore, the number of alleles per SSR locus detected in this study corresponded well with earlier reports (Jain et al., 2006; Joshi et al., 2010; Upadhyay et al., 2011 and Ramadan et al., 2015). However, other studies indicated 
higher allelic diversity, Jain et al., 2004 reported the number of alleles ranged between 3 and 22. The number of alleles is much affected by the technique used for diversity survey along with the kind of germplasm under study (Davierwala et al., 2000; Abdel-Rahman et al., 2013). Results in Table (3) indicated that SSR loci with simple tri-nucleotide repeat motifs generated the highest number of alleles (4 alleles per locus on average) followed by di-nucleotide repeats (3.11 alleles per locus in average). Similar results obtained by Juneja et al., (2006) and Behera et al., (2012). However, Cho et al., (2000) and Jain et al. (2004) observed that SSR loci with simple dinucleotide repeats detected a greater number of alleles than those with tri-nucleotide repeats. A negative correlation was detected between the number of repeats within a microsatellite marker and the number of alleles generated per locus (-0.331). However, a positive correlation between the number of repeats and the number of alleles amplified per locus was reported by $\mathrm{Ni}$ et al. (2002); Yu et al. (2003) and Ramadan et al. (2015). The difference in molecular size between the smallest allele and the largest allele for a given SSR locus ranged from 8 bp (RM5, RM223, and RM315) to 77 bp (RM10772). The lowest (120 bp) and the highest (442 bp) Amplicon sizes were generated by RM5 and RM 10772, respectively. A similar result was obtained by Ganie et al. (2016) who study the genetic diversity in Saltol QTL among 141 rice genotypes and obtained a high range of molecular sizes among the generated alleles. Among the amplified alleles, twenty $(41.67 \%)$ high frequency and twenty-eight $(58.33 \%)$ low-frequency alleles were identified over all the tested genotypes. On average, $59.13 \%$ of the tested genotypes shared the major frequency alleles at any of the tested loci. It ranged from 0.33 to 0.78 for RM562 and RM412, respectively (Table 3). Similar results were reported by Behera et al. (2012) when identified $34.56 \%$ high frequency and $61.03 \%$ low-frequency alleles among the used 38 high yielding rice varieties and 30 out of 31 primers amplified at least one high-frequency allele. Similar results were also observed by other investigators (Jayamani et al., 2007; Kaushik et al., 2011).

Table 3. Data generated by 14 SSR markers linked to salt tolerance QTLS overall the studied rice genotypes

\begin{tabular}{|l|c|c|c|c|c|c|}
\hline Marker & $\begin{array}{c}\text { No. of } \\
\text { Alleles } \\
\text { per locus }\end{array}$ & $\begin{array}{c}\text { Effective } \\
\text { number } \\
\text { of alleles }\end{array}$ & $\begin{array}{c}\text { Major } \\
\text { allele } \\
\text { frequency }\end{array}$ & $\begin{array}{c}\text { Amplicon } \\
\text { size (bp) }\end{array}$ & $\begin{array}{c}\text { Gene } \\
\text { diversity }\end{array}$ & PIC \\
\hline RM1287 & 4 & 2.63 & 0.50 & $147-180$ & 0.62 & 0.56 \\
\hline RM10711 & 5 & 1.61 & 0.78 & $150-167$ & 0.38 & 0.37 \\
\hline RM10720 & 3 & 2.44 & 0.56 & $173-237$ & 0.59 & 0.53 \\
\hline RM10772 & 3 & 1.79 & 0.72 & $365-442$ & 0.44 & 0.40 \\
\hline RM493 & 4 & 3.33 & 0.39 & $198-230$ & 0.70 & 0.64 \\
\hline RM140 & 4 & 1.82 & 0.72 & $240-268$ & 0.45 & 0.42 \\
\hline RM10825 & 2 & 1.79 & 0.72 & $184-202$ & 0.44 & 0.40 \\
\hline RM562 & 6 & 5.26 & 0.33 & $222-276$ & 0.81 & 0.79 \\
\hline RM9 & 2 & 1.92 & 0.67 & $126-186$ & 0.48 & 0.40 \\
\hline RM5 & 3 & 2.44 & 0.56 & $112-120$ & 0.59 & 0.52 \\
\hline RM212 & 3 & 1.79 & 0.72 & $118-142$ & 0.44 & 0.41 \\
\hline RM315 & 3 & 2.22 & 0.61 & $132-140$ & 0.55 & 0.49 \\
\hline RM223 & 3 & 2.63 & 0.50 & $150-158$ & 0.62 & 0.55 \\
\hline RM242 & 3 & 2.56 & 0.50 & $134-194$ & 0.61 & 0.54 \\
\hline Average & 3.43 & 2.45 & 0.59 & - & 0.55 & 0.50 \\
\hline
\end{tabular}

*Where PIC is polymorphic information content 


\section{Gene Diversity:}

Gene diversity or heterozygosity of a given locus refers to the probability that a genotype is heterozygous for this locus in the studied population (Liu, 1998). As shown in Table (3), the gene diversity estimates for the studied SSR loci ranged from 0.81 to 0.38 . High estimates were observed for RM562 (0.81), RM493 (0.70), and RM1287 (0.62) indicating the presence of high allelic diversity in Saltol locus. This result is in agreement with Jayabalana et al. (2019) who used 8 SSR markers tightly linked with Saltol QTL to study the genetic diversity in 47 rice genotypes and obtained high gene diversity values with an average of 0.65 .

Polymorphism Information Content (PIC):

The PIC value indicates the power of a marker locus to discriminate among the tested individuals. The PIC values for the 14 polymorphic SSR loci in our study varied from 0.79 (RM562) to 0.37 (RM10711) with an average of 0.50 (Table 3). Seven SSR markers i.e. RM562, RM493, RM1287, RM223, RM242, RM10720, and RM5 recorded high PIC values ranged from 0.79 to 0.52, according to Botstein et al. (1980), these markers are highly informative. The high estimates of PIC value recorded in the current study might be due to high genetic diversity in salinity tolerance QTLs among the studied genotypes. Similar to our findings, high PIC values ranged from 052 to 0.73 with the highest PIC value for RM562 were reported by Jayabalan et al. (2019). In another study, Ganie et al. (2016) reported that RM8094 followed by RM3412, RM562, and RM1287 were the most important and informative markers for studying the genetic diversity in Saltol QTL.

Figure 1A, shows the PCR amplified fragments produced by the highest polymorphic marker in the current study RM562 (PIC $=0.79)$ followed by RM493 $(\mathrm{PIC}=0.64)$ as well as the highest number of alleles (6 to 4 alleles per locus, respectively) suggesting that these markers could be useful for estimating the molecular genetic diversity among large number of rice germplasm.

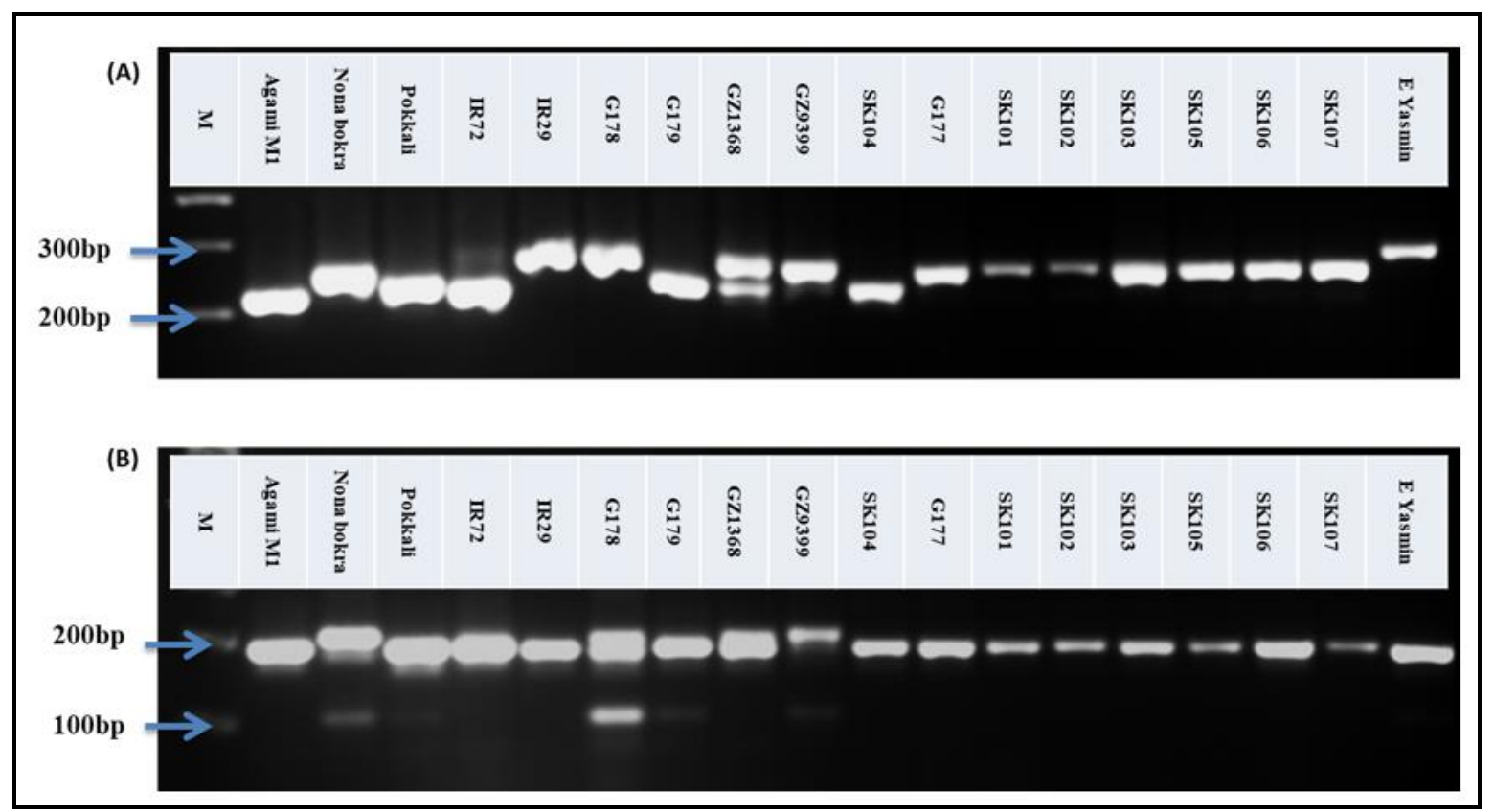

Fig. 1: DNA banding pattern of the eighteen genotypes. (A) With highly polymorphic microsatellite locus, RM562. (B) Microsatellite locus, RM10825. The lanes correspond to rice genotypes as given in Table 1. M- 100 bp DNA ladder. 


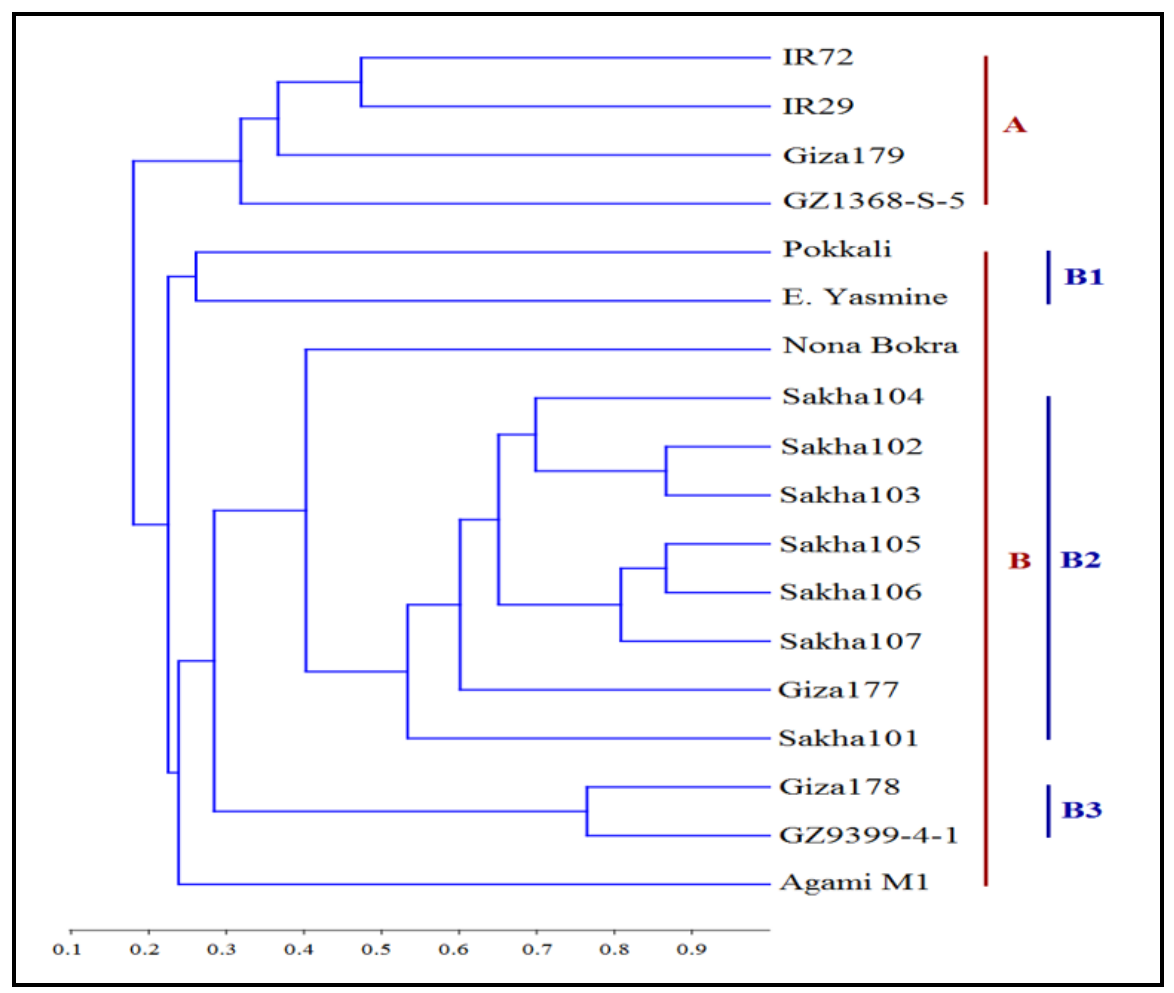

Fig. 2: UPGMA rooted dendogram showing genetic relationship among the tested genotypes based on similarity matrix derived from the 48 alleles at 14 polymorphic microsatellite loci. The major clusters are indicated by red lines.

Genetic Similarity and Relationship Among the Tested Rice Genotypes:

Genetic similarity coefficients of pair-wise comparisons estimated on the basis of the polymorphic microsatellite loci, ranged from 0.07 (between IR29 and Giza177) to 0.93 (between Sakha105 and each of Sakha106 and Sakha107) with an average of 0.45 , indicating a wide range of genetic variation among the tested genotypes using these set of SSR markers (Table 4). High similarity coefficients were recorded among the modern Egyptian rice cultivars Sakha104, Giza177, Sakha101, Sakha102, Sakha103, Sakha105, Sakha106, and Sakha107 since it ranged between 0.64 and 0.93 with an average of 0.78 . All of these cultivars are Japonica type and this obtained result indicates low genetic diversity among them when compared by other genotypes at the studied microsatellite loci. Moreover, Sakha 102, Sakha103, and Sakha106 Sharing Giza177 in their parentage, and all of them are susceptible to salinity stress. Among other genotypes, a high genetic similarity of
0.83 was recorded between both indica/japonica genotypes GZ9399-4-1-1-32-2 and its parent Giza178. On the other hand, low similarity coefficients were obtained between Agami M1 and both of Giza179 and E. Yasmine (0.14), and between Pokkali and each of and each of Giza179 (0.14), Nona bokra (0.21), and GZ1368-S-5 (0.25) despite their tolerance to salinity stress. These results indicate the presence of high allelic diversity in salinity tolerance QTLs and different tolerance mechanisms among the tolerant genotypes under the current study. Thomson et al. (2010) characterized Saltol QTL in rice using linked SSR markers and they found different alleles in this chromosomal region across different accessions of Pokkali landraces. In another study, Platten et al. (2013) reported that the Agami allele is unique when compared to 103 Asian and 12 African rice genotypes at the $S K C l$ gene of Saltol region. 
Table 4. Genetic similarity coefficient matrix among the tested genotypes using SSR markers

\begin{tabular}{|c|c|c|c|c|c|c|c|c|c|c|c|c|c|c|c|c|c|}
\hline Genotypes & 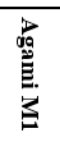 & 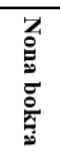 & 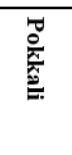 & 预 & 疍 & $\underset{\infty}{\stackrel{Q}{*}}$ & 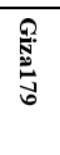 & 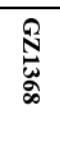 & 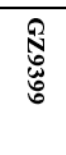 & 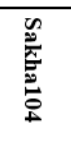 & 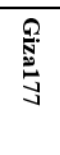 & 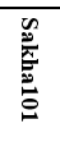 & 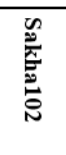 & 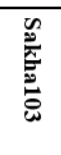 & 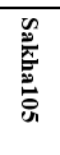 & 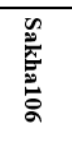 & 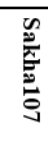 \\
\hline Nona bokra & 0.36 & & & & & & & & & & & & & & & & \\
\hline Pokkali & 0.36 & 0.21 & & & & & & & & & & & & & & & \\
\hline IR72 & 0.29 & 0.29 & 0.21 & & & & & & & & & & & & & & \\
\hline IR29 & 0.36 & 0.14 & 0.29 & 0.64 & & & & & & & & & & & & & \\
\hline Giza178 & 0.28 & 0.48 & 0.41 & 0.35 & 0.35 & & & & & & & & & & & & \\
\hline Giza179 & 0.14 & 0.50 & 0.14 & 0.57 & 0.50 & 0.48 & & & & & & & & & & & \\
\hline GZ1368 & 0.31 & 0.44 & 0.25 & 0.57 & 0.38 & 0.43 & 0.50 & & & & & & & & & & \\
\hline GZ9399 & 0.28 & 0.55 & 0.35 & 0.41 & 0.28 & 0.87 & 0.55 & 0.43 & & & & & & & & & \\
\hline $\begin{array}{l}\text { Sakha104 } \\
\end{array}$ & 0.57 & 0.57 & 0.43 & 0.21 & 0.14 & 0.35 & 0.21 & 0.25 & 0.35 & & & & & & & & \\
\hline Giza177 & 0.43 & 0.57 & 0.43 & 0.21 & 0.07 & 0.35 & 0.21 & 0.38 & 0.35 & 0.71 & & & & & & & \\
\hline Sakha101 & 0.36 & 0.43 & 0.50 & 0.29 & 0.14 & 0.55 & 0.29 & 0.44 & 0.48 & 0.79 & 0.64 & & & & & & \\
\hline Sakha102 & 0.43 & 0.64 & 0.43 & 0.29 & 0.14 & 0.35 & 0.29 & 0.31 & 0.48 & 0.86 & 0.79 & 0.71 & & & & & \\
\hline Sakha103 & 0.36 & 0.57 & 0.36 & 0.36 & 0.21 & 0.28 & 0.36 & 0.38 & 0.41 & 0.79 & 0.71 & 0.64 & 0.93 & & & & \\
\hline Sakha105 & 0.36 & 0.57 & 0.36 & 0.36 & 0.14 & 0.41 & 0.29 & 0.38 & 0.55 & 0.71 & 0.79 & 0.71 & 0.86 & 0.79 & & & \\
\hline Sakha106 & 0.36 & 0.57 & 0.43 & 0.29 & 0.14 & 0.35 & 0.29 & 0.31 & 0.48 & 0.71 & 0.79 & 0.64 & 0.86 & 0.79 & 0.93 & & \\
\hline Sakha107 & 0.43 & 0.64 & 0.36 & 0.43 & 0.21 & 0.48 & 0.36 & 0.44 & 0.62 & 0.71 & 0.71 & 0.71 & 0.86 & 0.79 & 0.93 & 0.86 & \\
\hline E. Yasmine & 0.14 & 0.21 & - & - & 0.41 & 0.40 & - & 0.18 & 0.33 & 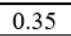 & 0.41 & 0.35 & 0.35 & 5 & 0.41 & 0.48 & \\
\hline
\end{tabular}

\section{Cluster Analysis:}

Cluster analysis based on Jaccard's similarity coefficients provided a clear resolution of relationships among all the studied genotypes. The studied genotypes were grouped into two major clusters at 0.18 similarity, Figure 2. Cluster A involved four rice genotypes i.e. the salt susceptible cultivar IR29, the moderately tolerant cultivar IR72, and both salt tolerance genotypes Giza179 and GZ1368-S-5. On the other hand, Cluster B included the salt tolerance Indica genotype Nona Bokra and the salt tolerance Japonica genotype Agami M1, and all other genotypes were grouped into three subclusters B1, B2, and B3. Both tolerance genotypes Pokkali and Egyptian Yasmine were grouped together into subcluster B1. Under subcluster B2, all modern japonica Egyptian rice cultivars i.e. Sakha104, Sakha102, Sakha103, Sakha105, Sakha106, Sakha107, Giza177, and Sakha101 were grouped together. Under subcluster B3 both tolerance genotypes Giza178 and GZ9399-4-1-1-3-2-2 were grouped together. These findings are agreed with the previous studies which reported the presence of different genotypes with different levels of salinity tolerance in the same group depending on Saltol DNA markers (Mohammadi-Nejad et al., 2008; Aliyu et al., 2011 and Chattopadhyay et al.,
2014). These results support the fact that salt tolerance is a polygenic trait and the probability of the presence of QTLs or genes other than Saltol in the studied rice genotypes.

\section{Principal Component Analysis:}

Principal component analysis (PCA) was carried out to study the genetic relationships among the current genotypes. The PCA analysis separated the studied genotypes into clearly four separate clusters based on their origin and salinity tolerance (Fig. 3). The first cluster was found in the $1^{\text {st }}$ quadrant and included both tolerant genotypes Agami M1 and Pokkali in addition to Egyptian Yasmine. The second cluster involved the susceptible variety IR29 and the moderately tolerance variety IR72 and it was found in the right corner of the $1^{\text {st }}$ quadrant. The salinity tolerance indica and indica/japonica genotypes Giza178, Giza179, GZ1368-S-5, and GZ9399-4-1-1-32-2 were clearly distinguished together in the third cluster which located in the $2^{\text {nd }}$ quadrant. Meanwhile, all other Egyptian Japonica cultivars come together in the fourth cluster in the left corner of the $3^{\text {rd }}$ and the $4^{\text {th }}$ quadrant. The salinity tolerance indica genotype Nona Bokra was located in the bottom corner of the $3^{\text {rd }}$ quadrant. The first five principal components scored the maximum Eigenvalues of $22.3 \%$ (PC1), 
$13.9 \%$ (PC2), $12.7 \%$ (PC3), $10.5 \%$ (PC4), and $8.4 \%$ (PC5) explaining the cumulative variation of $67.9 \%$ of the total variation among the studied genotypes. These results indicated the ability of PCA analysis to distinguish the tolerant genotypes form the susceptible ones based on the molecular data of the SSR markers used in the current study. These results are in agreement with Surapaneni et al. (2016) who reported the ability of PCA technique to partition the rice genotypes based on the variation in molecular and morphological data.

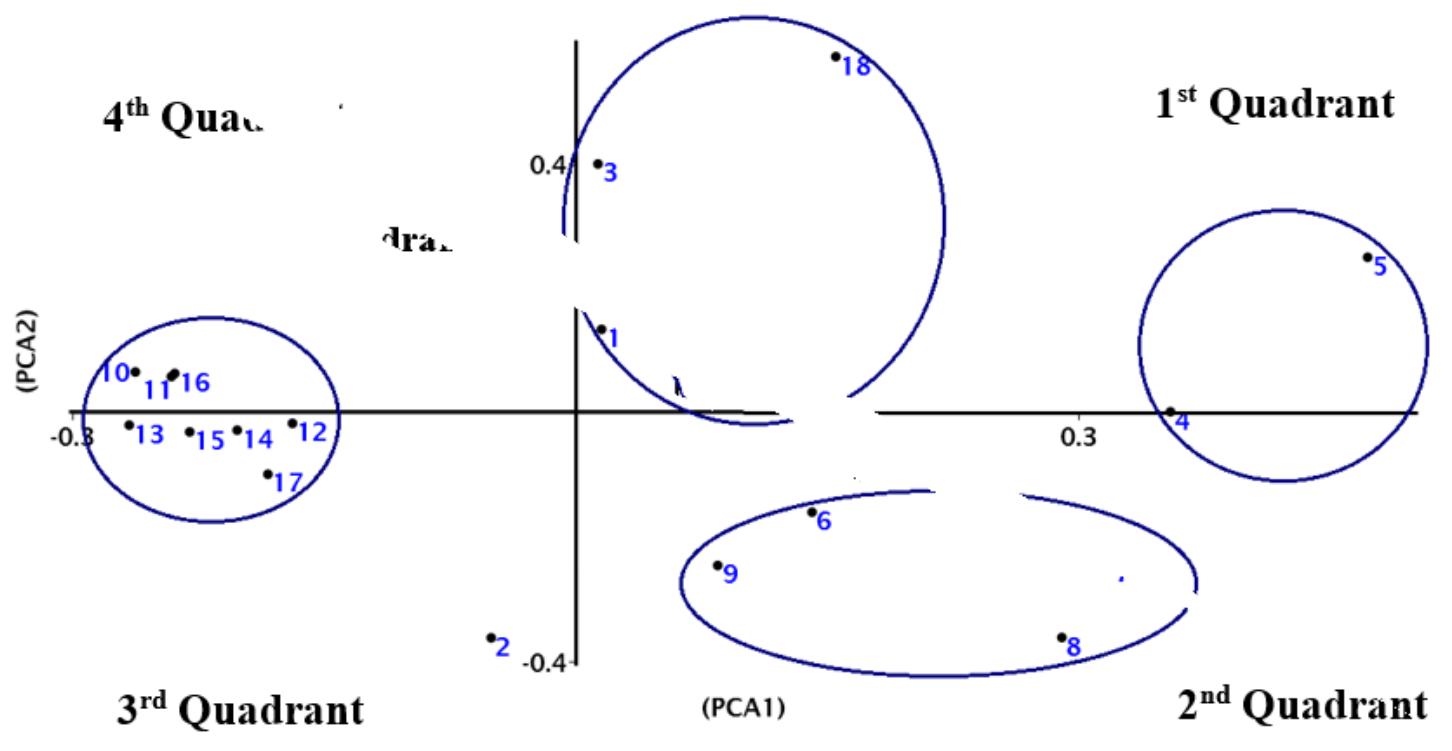

Figure 3: PCA based on the SSR marker based on similarity coefficients matrix.

\section{Haplotype Analysis:}

14 SSR markers closely linked with Saltol QTL were used for haplotyping the studied rice genotypes. Figure (4) showed that 14 haplotypes were identified including the main reference haplotype (Pokkali landrace). All other 13 haplotypes included one genotype for each haplotype except for haplotype 9 which included five rice cultivars i.e. Skha104, Sakha101, Sakha102, Sakha105, and Sakha107 and had four alleles common with Pokkali haplotype produced by RM10711, RM10825, RM9, and RM5. The number of alleles common with Pokkali differed overall the 13 haplotypes from one allele in haplotype6 which included Giza179 to six alleles in haplotype13 which included Egyptian Yasmine. Haplotype7 included two alleles; haplotypes $1,3,8$, and 11 included three alleles; haplotypes 4 and 5 included four alleles meanwhile haplotypes 2, 10, and 12 included five alleles. These results indicated that all tolerance genotypes shared Pokkali haplotype at least one allele at Saltol QTL. A high percentage of haplotypes had common alleles with Pokkali at RM10825 (82\%), RM10711 locus (76\%) and RM9 (71\%). Ganie et al. (2016) used four SSR markers closely linked to Saltol QTL i.e. RM1287, RM8094, RM562, and RM3412 for haplotyping 142 rice genotypes using FL478 as reference haplotype. They obtained nine haplotypes and one haplotype (haplotype2) formed by RM8094 and included the highest number of salt tolerance genotypes indicating the importance of this marker. In another study, Jayabalan et al. (2019) identified sixteen haplotypes using 6 Saltol QTL linked SSR markers. Based on the obtained results, the current study suggests the presence of a high amount of variation among the studied genotypes within Saltol QTL region. Also, the obtained results indicated the importance of haplotype 13 which includes Egyptian Yasmine and 
shared Pokkali at $50 \%$ of its alleles at the studied loci. This variety can be used as a salinity tolerance donor in the rice breeding program and MAS can be carried out in the segregated generations. Mekawy et al. (2015) reported that Egyptian Yasmine exhibited high expression of some membrane transporter/channel genes under salt stress that may contribute to $\mathrm{Na}^{+}$ exclusion from rice shoots (OsHKT1;5), limiting excess $\mathrm{Na}^{+}$entry into rice roots $(O s L t i 6 b), \mathrm{K}^{+}$uptake $(O s A K T 1)$, and reduced expression of $\mathrm{Na}^{+}$transporter gene (OsHKT2;1).

\begin{tabular}{|c|c|c|}
\hline Marker accession & Chr. & Position \\
& & \\
\hline RM1287 & 1 & $10,838,376-10,838,538$ \\
\hline RM10711 & 1 & $11,161,114-11,161,286$ \\
\hline RM10720 & 1 & $11,394,704-11,394,908$ \\
\hline RM10772 & 1 & $12,160,175-12,160,570$ \\
\hline RM493 & 1 & $12,280,117-12,280,294$ \\
\hline RM140 & 1 & $12,300,716-12,301,015$ \\
\hline RM10825 & 1 & $13,322,227-13,322,324$ \\
\hline RM562 & 1 & $14,626,324-14,626,568$ \\
\hline RM9 & 1 & $23,325,018-23,325,199$ \\
\hline RM5 & 1 & $23,971,321-23,971,514$ \\
\hline RM212 & 1 & $33,053,493-33,053,654$ \\
\hline RM315 & 1 & $36,734,135-36,734,272$ \\
\hline
\end{tabular}

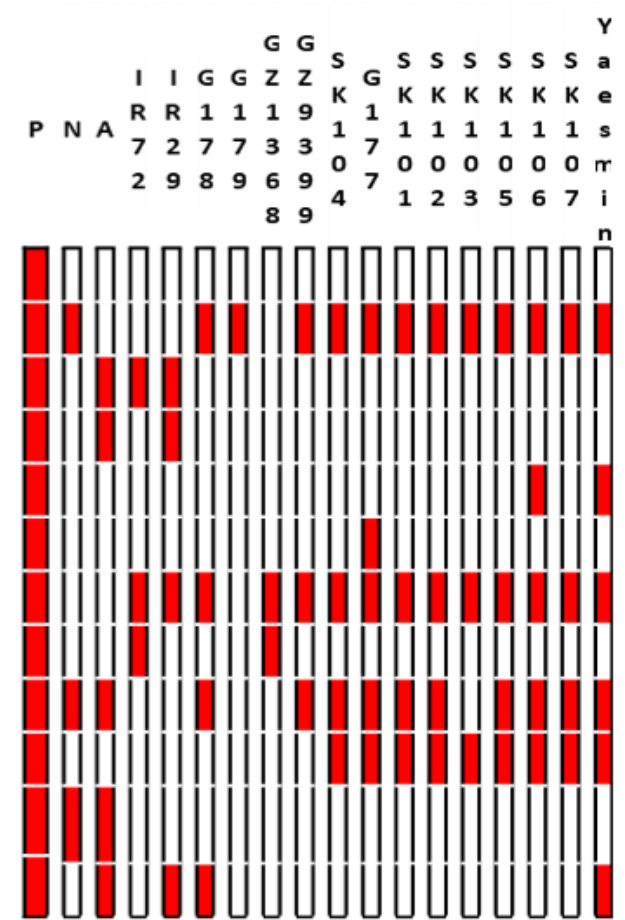

Fig. 4: diagrammatic representation of the marker screening across the saltol locus in the studied genotypes as compared to the pokkali $(\mathrm{P})$ genomic region. $\mathrm{N}$ : nona bokra and $\mathrm{A}$ : Agami M1.

\section{Conclusion}

Genetic diversity is the first step for any successful breeding program. The results of the current study indicated a wide range of molecular variation within salinity tolerance QTLs among the studied genotypes. The high values of PIC supported the suitability of SSR markers used in the current investigation for studying genetic variability in different rice populations. PCA analysis divided the rice genotypes into four groups depending on their tolerance and subspecies. Results of haplotyping revealed the importance of the aromatic variety Egyptian Yasmine as salinity tolerant donor

Acknowledgment:

The authors would like to acknowledge the financial support of the
Misr Elkheir Foundation and the Field Crops Research Institute.

\section{REFERENCES}

Abdel-Rahman, M.A., Abdelkhalik, A.F. and Dora, S.A. (2013) Molecular genetic diversity for eight rice genotypes with different drought responses using SSR markers. Journal of Agricultural Research Kafrelsheikh Univiverity. 39(1), 107-122.

Akagi, H., Yokozeki, Y., Inagaki, A. and Fujimura, T. (1996) Microsatellite DNA markers for rice chromosomes. Theoretical and applied genetics. 94, 61-67.

Anderson, J.A., Churchill, G.A., Autrique, J.E., Tanksley, S.D. and Sorrells, M.E. (1993) Optimizing parental 
selection for genetic linkage maps. Genome. 36(1), 181-186.

Behera, L., Sahu, R.K., Datta, S., Nanda, A., Sahu, S.C., Pradhan, S.K., Rao, G.J.N. and Singh, O.N. (2012) DNA fingerprinting and assessment of genetic diversity of high yielding rice varieties using microsatellite markers. International journal of environment, agriculture and biotec hnolog,. 5(2), 89-99.

Bonilla, P., Dvorak, J., Mackill, D., Deal, K. and Gregorio, G. (2002) RLFP and SSLP mapping of salinity tolerance genes in chromosome 1 of rice (Oryza sativa L.) using recombinant inbred lines. Philippine Agricultural Scientist, 85, 68-76.

Botstein, D., White, R.L., Skolnick, M. and Davis, R.W. (1980) Construction of a genetic linkage map in man using restriction fragment length polymorphism. American Journal of Human Genetics, 32: 314- 331

Chattopadhyay, K., Nath, D., Mohanta, R.L., Bhattacharyya, S., Marndi, B.C., Nayak, A.K., Singh, D.P., Sarkar, R.K. and Singh, O.N. (2014) Diversity and validation of microsatellite markers in Saltol QTL region in contrasting rice genotypes for salt tolerance at the early vegetative stage. Australian Journal of Crop Science, 8(3), 356-362

Cho, Y.G., Ishii, T., Temnykh, S.V, Chen, X., Lipovich, L., McCouch, S.R., Park, W.D., Ayres, N.M. and Cartinhour, S. (2000) Diversity of microsatellites derived from genomic libraries and GenBank sequences in rice (Oryza sativa L.). Theoretical and applied genetics, 100(5), 713722.

Davierwala, A.P., Chowdari, K.V., Kumar, S., Reddy, A.P.K., Ranjekar, P.K., and Gupta, V.S. (2000) Use of three different marker systems to estimate genetic diversity of Indian elite rice varieties. Genetica, 108(3), 269-284.
Ganie S.A., Borgohain, M.J., Talukdar, K.K.A., Pani, D.R. and Mondal, T.K. (2016) Assessment of genetic diversity of Saltol QTL among the rice (Oryza sativa L.) genotypes. Physiology and Molecular Biology of Plants, 22(1), 107-114

Ganie, S.A. and Mondal, T.K. (2015) Genome-wide development of novel miRNA-based microsatellite markers of rice (Oryza sativa) for genotyping applications. Molecular Breeding, 35, 1-12

Aliyu, R., Adamu, A.K., Muazu, S. and So, A. and Gregorio, G.B. (2011) Tagging and validation of SSR markers to salinity tolerance QTLs in rice (Oryza spp). International conference on biology, environment and chemistry IPCBEE vol.1, IACSIT Press, Singapore, p 328-332

Gregorio, G.B. (1997) Tagging salinity tolerant genes in rice using Amplified Fragment Length Polymorphism (AFLP). Ph.D. Dissertation. University of the Philippines Los Baños College, Laguna, Philippines, p. 118.

Reddy I.N.B.L., Kim, S.M., Kim, B.K., Yoon, I.S. and Kwon, T.R. (2017) Identification of rice accessions associated with $\mathrm{K}^{+} / \mathrm{Na}^{+}$ratio and salt tolerance based on physiological and molecular responses. Rice Science, 24(6), 360-364

Ismail, A.M., Thomson, M.J., Singh, R.K., Gregorio, G.B. and Mackill, D.J. (2008) Designing rice varieties adapted to coastal areas of South and Southeast Asia. Journal of the indian society of coastal agricultural research, 26, 69-73.

Jain, N., Jain, S., Saini, N., and Jain, R.K. (2006) SSR analysis of chromosome 8 regions associated with aroma and cooked kernel elongation in Basmati rice. Euphytica, 152(2), 259-273.

Jain, S., Jain, R.K. and McCouch, S.R. (2004) Genetic analysis of Indian aromatic and quality rice (Oryza 
sativa L.) germplasm using panels of fluorescently-labeled microsatellite markers. Theoretical and Applied Genetics, 109(5), 965-77

Jayabalana, S., Pulipatia, S., Ramasamya, K., Jaganathana, D., Venkatesanb, S.D., Vijay, G., Kumari, K., Raju, K., Hariharan, G. N. and Venkataraman G. (2019). Analysis of genetic diversity and population structure using SSR markers and validation of a Cleavage Amplified Polymorphic Sequences (CAPS) marker involving the sodium transporter OsHKT1;5 in saline tolerant rice (Oryza sativa L.) landraces. Gene, 713: 143976

Jayamani, P., Negrão, S., Martins, M., Maçãs, B. and Oliveira, M.M. (2007) Genetic relatedness of Portuguese rice accessions from diverse origins as assessed by microsatellite markers. Crop Science, 47(2), 879-886.

Joshi, R.K., Subudhi, E., Kar, B. and Nayak, S. (2010) Comparative genetic analysis of lowland rice cultivars of India using microsatellite markers. Bioresearch Bulletin, 4 , 213-223.

Juneja, S., Das A., Joshi, S.V., Sharma S., Vikal, Y., Patra, B.C., Bharaj, T.S., Sidhu, J.S. and Singh, K. (2006) Oryza nivara (Sharma et Shastry) the progenitor of $O$. sativa (L.) subspecies indica harbours rich genetic diversity as measured by SSR markers. Current Science, 91: 10791085.

Kaushik, A., Jain, S., McCouch, S.R. and Jain, R.K. (2011) Phylogenetic relationships among various groups of rice (Oryza sativa L.) as revealed by microsatellite and transposable element-based marker analysis. Indian Journal of Genetics and Plant Breeding, 71(2), 139-150.

Liu, B.H. (1998) Statistical genomics: linkage, mapping and QTL analysis. CRC Press, Boca Raton, 611 pp.

Liu, K., and Muse, S.V. (2005) PowerMarker: an integrated analysis environment for genetic marker analysis. Bioinformatics, 21(9), 21282129.

Surapaneni, M., Balakrishnan, D., Mesapogu, S., Raju, A.K., Rao, Y.V. and Neelamraju, S. (2016) Genetic characterization and population structure of Indian rice cultivars and wild genotypes using core set markers. 3 Biotech, 6:95

McCouch, S.R., Chen, X., Panaud, O., Temnykh, S., Xu, Y., Cho, Y.G., Huang, N., Ishii, T. and and Blair, M. (1997) Microsatellite marker development, mapping and applications in rice genetics and breeding. In Oryza: From Molecule to Plant (pp. 89-99). Springer, Dordrecht.

Mekawy, A.M.M., Assaha, D.V.M., Yahagi, H., Tada, Y., Ueda and A., Saneoka, H. (2015) Growth, physiological adaptation, and gene expression analysis of two Egyptian rice cultivars under salt stress. Plant Physiology and Biochemistry, 87,1725

Mohammadi-Nejad, G., Arzani, A., Rezai, A.M., Singh, R.K. and Gregorio G.B. (2008) Assessment of rice genotypes for salt tolerance using microsatellite markers associated with the saltol QTL. African Journal of Biotechnology. 7, 730-736

Murray, A. A. and W. F. Thompson (1980). Rapid isolation of high molecular weight plant DNA. Nucleic Acids Research, 8, 4321-4326.

Nei, M. and Li, W.H. (1979) Mathematical models for studying genetic variation in terms of restriction endonucleases. Proceedings of the National Academy of Sciences of the United States of America, 76, 5269-5273.

Ni, J., Colowit, P.M. and Mackill, D.J., (2002) Evaluation of genetic diversity in rice subspecies using microsatellite markers. Crop Science, 42(2), 601-607. 
Niones, J.M. (2004) Fine mapping of the salinity tolerance gene on chromosome 1 of rice (Oryza sativa L.) using near isogenic lines. MS dissertation. College, Laguna, Philippines: University of the Philippines Los Baños, Laguna.

Orjuela, J., Andrea, G., Matthieu, B., Arbelaez, J.D., Moreno, L., Kimball, J., Wilson, G., Rami, J., Joe, T., McCouch, S.R. and Lorieux, M. (2010) A universal core genetic map for rice. Theoretical and applied genetics, 120, 563-572

Platten, J.D., Egdane, J.A. and Ismail, A.M. (2013) Salinity tolerance, $\mathrm{Na}^{+}$ exclusion and allele mining of HKT1; 5 in Oryza sativa and $O$. glaberrima: many sources, many genes, one mechanism?. BMC Plant Biology, 13, 32.

Ramadan, E.A., Elmoghazy, A.M., and ElMowafi, H.F. (2015) Molecular markers based genetic diversity analysis for drought tolerance in rice (Oryza sativa, L.) using SSR markers. International Journal of Agricultural Science Research,2, 137-146.

Rani, M.G. and Adilakshmi, D. (2011) Genetic analysis of blast resistance in rice with simple sequence repeats (SSR). Journal of Crop Improvement, 25, 232-238

Ren, Z.H., Gao, J.P., Li, L.G., Cai, X.L., Huang, W., Chao, D.Y., Zhu, M.Z., Wang, Z.Y., Luan, S. and Lin, H.X. (2005). A rice quantitative trait locus for salt tolerance encodes a sodium transporter. Nature Genetics, 37(10), 1141-6.

Stanley, J.D. and Clemente, P.L. (2017) Increased land subsidence and sealevel rise are submerging Egypt's Nile Delta coastal margin. GSA Today, 27(5), 4-11.

Takehisa, H., Shimoda, Y., Fukuta, T., Ueda, M., Yano, T., Yamaya, T., Kameya, T. and Sato, T. (2004) Identification of quantitative trait loci for plant growth of rice in paddy field flooded with salt water. Field Crops Research, 89, 85-95

Thomson, M.J., de Ocampo, M., Egdane, J., Rahman, M.A., Sajise, A.G., Adorada, D.L., Raiz, E.T., Blumwald, E., Seraj, Z.I., Sing, R.K., Gregorio, G.B. and Ismail, A. M. (2010). Characterizing the Saltol Quantitative Trait Locus for Salinity Tolerance in Rice. Rice, 3, 148-160

Upadhyay, P., Singh, V.K., Neeraja, C.N. (2011) Identification of genotype specific alleles and molecular diversity assessment of popular rice (Oryza sativa L.) varieties of India. International Journal of Plant Breeding and Genetics, 5(2), 130140.

Weir, B.S. (1989) Sampling properties of gene diversity. In: Brownp, A.H.D., Clegg, M.T., Kahler, H.L. and Weir, B.S. (eds) PLANT POPULATION GENETICS, BREEDING AND GENETIC RESOURCES. Sinauer Associates, Sunderland, Massachusetts, pp 23-42

Wu, K.S. and Tanksley, S.D. (1993) Abundance, polymorphism and genetic mapping of microsatellites in rice. Molecular genetics and genomics, 241, 225-235.

Yu, S.B., Xu, W.J., Vijayakumar, C.H.M., Ali, J., Fu, B.Y., Xu, J.L., Jiang, Y.Z., Marghirang, R., Domingo, J., Aquino, C. and Virmani, S.S. (2003) Molecular diversity and multilocus organization of the parental lines used in the International Rice Molecular Breeding Program. Theortical and Applied Genetics, 108(1), 131-140.

Zayed, B.A., El-Kellawy, W.H., Okasha, A.M. and Abd El-Hamed, M.M. (2017) Improvement of salinity soil properties and rice productivity under different irrigation intervals and gypsum rates. Journal of Plant Production, 8(3), 361-368. 